\section{Acrodermatitis Continua of Hallopeau with Unusual Features}

\section{Ravikumar BC*, Suchetha Subba Swamy and Vinay KN}

Department of Dermatology, Venereology \& Leprosy, Hassan Institute of Medical Sciences, Hassan, India

\begin{abstract}
Acrodermatitis Continua of Hallopeau $(\mathrm{ACH})$ is a rare clinical entity characterized by sterile pustular eruptions on the hands and feet. It is often considered to be a variant of pustular psoriasis with a chronic relapsing course that tends to be resistant to both topical and systemic treatments for psoriasis. Though $\mathrm{ACH}$ may present with paronychia, onychodystrophy and osteolysis of the distal phalanges of the fingers and toes, deformities in the form of auto amputation of the digits and toes has not been reported in the literature. We report this patient with $\mathrm{ACH}$ who presented to us with unusual features of auto amputation of toes.
\end{abstract}

Keywords: Acrodermatitis; Auto amputation; Continua; Hallopeau

\section{Introduction}

Acrodermatitis Continua of Hallopeau (ACH) is an uncommon clinical entity characterized by sterile pustular eruptions on the hands and feet. The disease has a relapsing course [1] and it predominantly affects the fingertips with nail involvement [2]. ACH is most common in middle aged women [3] and is rarely reported in Indian literature. Though ACH may present with paronychia, onychodystrophy and osteolysis of the distal phalanges of the fingers and toes, severe deformity like auto amputation of the fingers and toes is hither to unreported. We are reporting this case of $\mathrm{ACH}$ in a 60 year old male because of its rarity in Indian literature and also because of the unusual deformity witnessed in this patient.

\section{Case Report}

A 60 year old male presented with history of recurrent flares of painful pustular and scaly lesions on distal portion of all toes since 47 years. On examination, erythematosquamous lesions were present over dorsal aspect of right great toe. There was shortening of all toes except right great toe (Figure 1). Dystrophic changes were seen over the nails of bilateral great toes. There was no history of surgical

*Corresponding author: Ravikumar BC, Department of Dermatology, Venereology \& Leprosy, Hassan Institute of Medical Sciences, Hassan, India, Tel: +91 9448742905; E-mail: dr.ravikumarbc@gmail.com

Citation: Ravikumar BC, Swamy SS, Vinay KN (2015) Acrodermatitis Continua of Hallopeau with Unusual Features. J Clin Dermatol Ther 2: 012.

Received: April 20, 2015; Accepted: July 16, 2015; Published: July 30, 2015 amputation of the toes. There was no personal or family history of psoriasis or diabetes mellitus. The patient's medical history was otherwise unremarkable. Peripheral pulses and peripheral sensations were normal. The patient was a non smoker and there was no history of similar complaints among any of the family members. The patient had taken several medications in the form of various antibiotics, antifungals and corticosteroids both topically and orally.

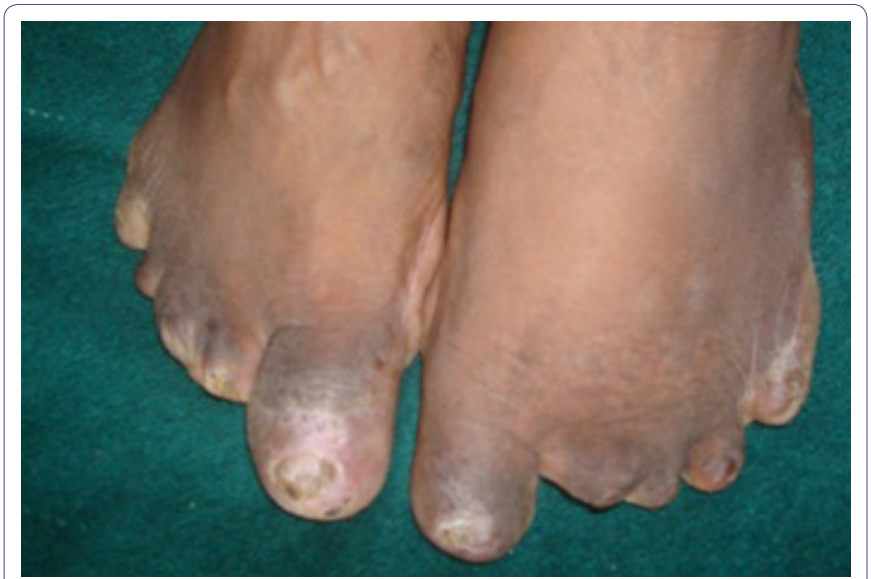

Figure 1: Erythemato squamous lesions over dorsal aspect of right great toe with shortening of all toes except right great toe. Note the dystrophic changes over the nails of bilateral great toes.

The bacterial culture from the pustule did not show any bacterial growth. $\mathrm{KOH}$ mount from skin lesions and the nail clippings was negative for fungal filaments.

X-ray of both feet showed resorption of middle and distal phalanges of all toes except the right great toe bilaterally and partial resorption of proximal phalanx of left great toe (Figure 2).

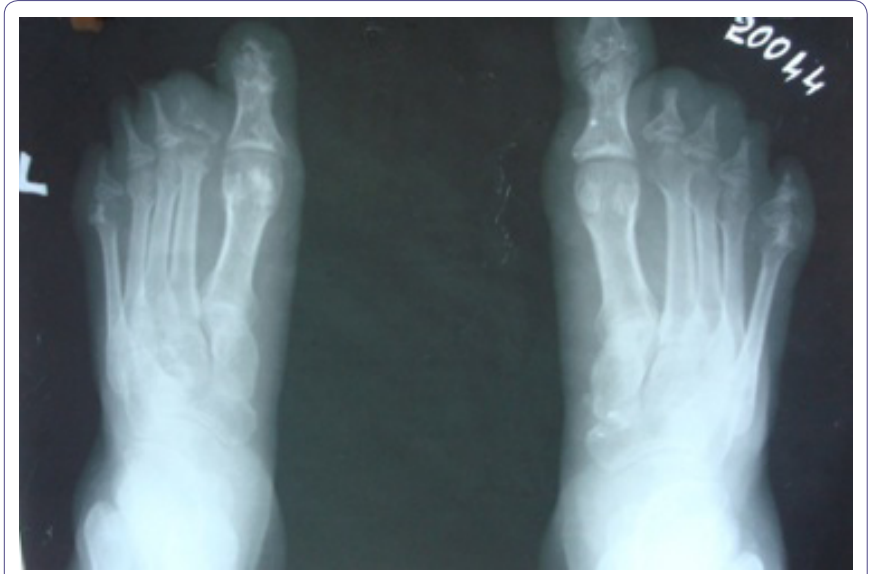

Figure 2: X-ray of feet showing resorption of middle and distal phalanges of the lateral four toes bilaterally and partial resorption of proximal phalanx of left great toe.

Histopathological examination of the lesion revealed psoriatic changes with elongated rete ridges, mild acanthosis with parakeratosis. Dermis showed dilated blood vessels with perivascular edema and infiltration of lymphocytes and neutrophils (Figure 3). 


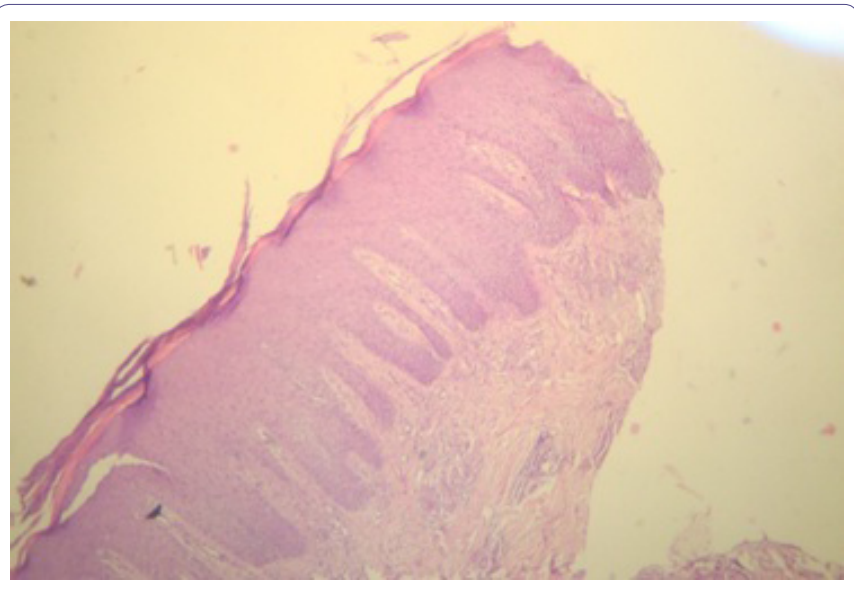

Figure 3: Histopathological examination of the lesion showing psoriatic changes with elongated rete ridges, mild acanthosis with parakeratosis. Dermis shows dilated blood vessels with perivascular edema and infiltration of lymphocytes and neutrophils.

All the other investigations including complete haemogram, liver and renal functions tests were normal. Tests for HIV, HBs Ag were also negative.

Based on clinical and histopathological findings, a diagnosis of Acrodermatitis Continua of Hallopeau was made. We treated the patient initially conservatively with oral antibiotics and topical steroids. Since no improvement was achieved, we started oral pentoxifylline with which the patient could find some relief in the form of alleviation of pain. We are planning to start the patient on TNF- $\alpha$ inhibitors during the next follow up.

\section{Discussion}

Acrodermatitis Continua of Hallopeau $(\mathrm{ACH})$ is a rare, chronic, localized sterile pustular eruption of the fingers and toes [4]. Although it is generally considered to be a variant of pustular psoriasis, some people classify it as a separate entity [5]. It is most common in middle-aged women and often begins after localized trauma or infection on a single digit.

$\mathrm{ACH}$ presents with multiple pustules and scales on an erythematous base and is usually restricted to a distal aspect of one or two digits. The pustules may coalesce to form lakes of pus and may spread proximally to involve dorsal aspect of hands, forearms and feet [3]. The disease process may result in sclerosis and osteolysis if left untreated [1]. In addition, onychodystrophy and anonychia can result from pustulation of the nail bed and nail matrix $[1,3,6]$. Auto amputation witnessed in our patient is unusual in $\mathrm{ACH}$.

Histologically, ACH displays features of pustular psoriasis that include sub corneal neutrophilic pustules and spongiform pustules of kogoj, with a lymphohistiocytic infiltrate and focal edema of the superficial dermis $[3,7]$.X-ray may reveal atrophy of the distal phalanx and arthropathy of interphalangeal joints [8].
Several diseases mimic ACH like parakeratosis pustulosa, pustular psoriasis, contact dermatitis, atopic dermatitis, tinea pedis, paronychia, dry fissured eczematoid dermatitis and pemphigus vegetans. $\mathrm{ACH}$ can be differentiated from all these entities by the characteristic clinical findings, absence of contact sensitizing agents, other features of atopic diathesis, fungal filaments on $\mathrm{KOH}$ mount, immunofluorescence and so on.

Treatment of ACH is difficult and often disappointing. Topical treatments tried are glucocorticoids, calcipotriol, 5-fluorouracil, tar, dithranol, calcineurin inhibitors, NB-UVB [9]. Systemic treatments include oral retinoids, cyclosporine, methotrexate combined with oral propylthiouracil, PUVA, dapsone, thalidomide in association with ultraviolet rays and tetracyclines. However recent reports have suggested promising results with infliximab, etanercept, adalimumab, efalizumab $[7,10]$. But larger studies are needed to prove that these medications are consistently effective in controlling the disease.

We have reported this male patient with $\mathrm{ACH}$ because of the hitherto unreported severe morbidity in the form of pain and autoamputation of toes.

\section{References}

1. Sopkovich JA, Anetakis Poulos G, Wong HK (2012) Acrodermatitis continua of hallopeau successfully treated with adalimumab. J Clin Aesthet Dermatol 5: 60-62.

2. Abbas O, Itani S, Ghosn S, Kibbi AG, Fidawi G, et al. (2013) Acrodermatitis continua of Hallopeau is a clinical phenotype of DITRA: evidence that it is a variant of pustular psoriasis. Dermatology 226: 28-31.

3. Rosenberg BE, Strober BE (2004) Acrodermatitis continua. Dermatol Online J 10: 9.

4. Yerushalmi J, Grunwald MH, Hallel-Halevy D, Avinoach I, Halevy S (2000) Chronic pustular eruption of the thumbs. Diagnosis: Acrodermatitis Continua of Hallopeau (ACH). Arch Dermatol 136: 925-930.

5. Gluckman SJ, Heyman W (2001) Diagnosis: acrodermatitis continua of Hallopeau. Clin Infect Dis 32: 431, 505.

6. Silpa-archa N, Wongpraparut C (2011) A recalcitrant acrodermatitis continua of Hallopeau successfully treated with etanercept. J Med Assoc Thai 94: 1154-1157.

7. Dini V, Barbanera S, Romanelli M (2013) Efficacy of adalimumab for the treatment of refractory paediatric acrodermatitis continua of hallopeau. Acta Derm Venereol 93: 588-589.

8. Mrowietz ECU (2003) Pustular Eruptions of Palms and Soles. In: Wolff K, Goldsmith LA, Katz SI, Gilchrist BA, Paller AS (eds.). Fitzpatrick's Dermatology in General Medicine. ( $7^{\text {th }}$ edn), McGraw Hill, Philadelphia, USA. Pg no: 217-218.

9. Bordignon M, Zattra E, Albertin C, Belloni-Fortina A (2010) Successful treatment of a 9-year-old boy affected by acrodermatitis continua of Hallopeau with targeted ultraviolet B narrow-band phototherapy. Photodermatol Photoimmunol Photomed 26: 41-43.

10. Balato N, Gallo L, Balato A, La Bella S, Ayala F (2009) Acrodermatitis continua of Hallopeau responding to efalizumab therapy. J Eur Acad Dermatol Venereol 23: 1329-1330. 